\section{La Virtud de la Humildad en la Práctica del Médico}

\section{The Virtue of Humility in the Physician Practice}

\section{Señor Editor:}

Aun cuando se escribe muy poco sobre las virtudes en las revistas médicas, me parece de interés abordar el tema, porque estimo que siguen siendo muy importantes en la práctica del médico. Se ha manifestado la necesidad perentoria de revitalizar las virtudes en el ejercicio de la Medicina ${ }^{1}$, aparte de considerarse fundamento de la formación médica ${ }^{2}$.

Ninguna de las virtudes está ajena a la personalidad moral, o ethos del médico. Entre ellas, la prudencia, compasión, beneficencia, honestidad, respeto, etc., pero hay una que no brilla mucho entre los profesionales médicos, y pasa a ser una característica percibida negativamente por muchos pacientes y que por ello, vale la pena intentar mejorar. Me refiero a la Humildad, virtud valorizada desde todas les religiones y espiritualidades.

La Humildad del médico, además de lograr una mejor comunicación con los pacientes y lograr mejores resultados en su salud, ${ }^{3}$ permite en su calidad de virtud propiamente tal y en su sentido clásico, la perfección del acto médico y de la propia naturaleza del médico. La humildad, como todas las virtudes, es tarea moral de todo médico, y puede ser cultivada-no sin esfuerzo-a través de actos buenos repetitivos y enseñada principalmente a través del ejemplo. Esta tarea moral ya la señalaba con toda claridad, entre otros, y hace muchos años, Dante Alighieri: "Fuimos creados no para vivir como bestias, sino para la prosecución de la virtud y del conocimiento".

La palabra Humildad proveniente del latín huminitas y también de humus, tierra vegetal, descompuesta; que debiera ayudar al hombre en general a no olvidar su origen y destino común en cuanto materia, independiente de sexo, edad, etnia, situación económica-social, profesión u oficio.

Es posible distinguir en la práctica del médico, algunas manifestaciones, muy estrechamente relacionadas, que conforman esta virtud ${ }^{4}$.

La humildad involucra, en primer término, aceptación y reconocimiento de las propias limitaciones y deficiencias. Nadie es perfecto. "Humildad es mirarnos como somos - sin paliativos- con la verdad". Hay que tener en cuenta que las condiciones médicas pueden ser muchas veces desconcertantes. Así, los síntomas de los pacientes pueden ser vagos o inconsistentes con un trastorno conocido, o la efectividad del tratamiento puede no ser una certeza, haciendo deficitaria la acción médica. A manera de ejemplo, entre muchos posibles, el diagnóstico en algunos pacientes de una condición como la taquicardia postural ortostática, puede tardar hasta 10 años, después haber comenzado las moles- tias, a pesar de innumerables consultas previas de los enfermos ${ }^{5}$.

La Humildad también significa capacidad para reconocer los errores cometidos. Sin el reconocimiento de ellos no es posible rectificarlos, ni prevenirlos. Muchas veces, subyace al error médico, una carencia de las virtudes requeridas para ejercer la Medicina. Sin reconocimiento del error, no tiene cabida la petición de perdón.

La Humildad, por otra parte, capacita al médico para modelar su egoísmo, y en consecuencia posponer su propio interés en beneficio del paciente. El médico humilde sabe que puede aprender de los demás, de sus colegas y pacientes, y se interesa por los otros.

Otra manifestación de la Humildad es la gratitud. Ser humilde es ser agradecido para aquellos maestros y pacientes que han sido instrumentos de aprendizaje en todo momento de su caminar. Es ser capaz de agradecer día tras día la hermosa oportunidad de servir a tantas personas enfermas en el ejercicio abnegado de la profesión. Al médico orgulloso le costará mucho ser agradecido, porque cree y siente que todo se lo merece. La práctica de la gratitud -que puede ser desarrollada voluntariamente- produce además beneficios para la salud mental del propio médico.

He dejado para el último, otro componente de la humildad, la ausencia de soberbia La humildad se contrapone al orgullo, la arrogancia. El famoso médico ruso Iván Pavlov, Premio Nobel de Medicina en 1904, escribía en su testamento, dedicado a los jóvenes de su patria: "Huid del orgullo como de una peste mortal. Por orgullo os volveréis tercos, donde deberíais ceder. Por orgullo vais a rechazar el consejo útil y la ayuda amistosa; por orgullo vais a perder la medida para la objetividad". La soberbia del ser humano, y del médico, es posible que obedezca al olvido que los dones de los que tanto se vanagloria, son precisamente dones, es decir, le fueron dados a su naturaleza. Olvida que "El médico es instrumento de sanación, no su fuente". Solo el médico humilde podrá emular la actitud de aquel doctor compasivo que no tiene reparo alguno, en arrodillarse para cortar las uñas de un sufriente anciano en una biblioteca, tal como relata de manera ejemplar Richard Selzer, cirujano escritor, en su famoso cuento “Toenails", escrito en 1982. El médico soberbio, que cree saber todo y mejor que nadie, que se siente omnisciente, no será nunca capaz de preguntar a un colega sobre un caso difícil y perderá la oportunidad de ayudar de mejor forma a su paciente. El médico soberbio, ciego a su verdadera y limitada realidad, no está en disposición a servir y por consiguiente no podrá ejercer la medicina con benevolencia, ya que ésta, no es otra cosa que una relación de ayuda, de servicio. Solo el médico humilde podrá tener el maravilloso privilegio de servir a otro que lo necesita en su padecer, dando significado pleno al verbo transitivo servir. El médico 
soberbio se encarama en lo alto de un pedestal construido por el mismo, afectado de esa enfermedad, tan ingeniosamente llamada por un colega argentino como "broncemia", o "bronceosis", ${ }^{6}$ en la que plena su sangre de bronce, se erige como estatua olímpica e inmortal, de donde no podrá descender nunca como un servidor. De esa manera no podrá ser feliz ni cumplir cabalmente su rol de médico al servicio de los enfermos. Gabriela Mistral, Premio Nobel de Literatura en 1945, escribía en este sentido, en su hermoso poema, el Placer de Servir: "Existe la alegría de ser sano y de ser justo, pero hay sobre todo, la hermosa alegría de servir".

Alexis Lama Toro ${ }^{1}$ ${ }^{1}$ Cardiólogo Centro Médico IntegraMédica.

\section{Referencias}

1. Bain LE. Revisiting the need for virtue in medical practice: a reflection upon the teaching of Edmund Pellegrino. Philos Ethics Humanit Med 2018; 13 (1): 4.
2. Seoane L, Tompkins L, Conciliis A, Boysen P. Virtues Education in Medical School: The Foundation for Professional Formation. Ochsner Journal 2016; 16: 50-5.

3. Ruberton P, Huynh H, Miller T, Kruse E, Canciller J, Lyubomirsky S. The relationship between physician humility, physician-patient communication, and patient health. Pacientes Educ Couns, 2016; 99 (7):1138-45.

4. Coulehan J. "A Gentle and Humane Temper" humility in medicine Perspectives in Biology and Medicine 2011; 54: 206-16.

5. Jiménez P, Earle N, González B, Tieck E. Taquicardia postural ortostática en 15 pacientes: disautonomía compleja. Rev Med Chile 2012; 140: 145-2.

6. Young P. Bronceosis: enfermedad especulativa por depósito de bronce. Rev Med Chile 2012; 140: 824-5.

Correspondencia a:

Dr. Alexis Lama

San Sebastián 2953 Dpto. 22, Las Condes.

lamatoro@yahoo.es 